Original article

\title{
Electron microscopic study of changes in pancreatic exocrine secretory cells in both early and late stages of hypothyroidism
}

\author{
Olga V. Ostapenko, Maxim A. Kriventsov, Yuliana I. Shramko, Yulianna A. Yermola, Elena M. Mostiuk
}

V.I. Vernadsky Crimean Federal University, Simferopol, Russia

Received 23 January 2019, Accepted 14 May 2019

C 2019, Ostapenko O.V., Kriventsov M.A., Shramko Y.I., Yermola Y.A., Mostiuk E.M.

(C) 2019, Russian Open Medical Journal

\begin{abstract}
Aim of this study was to evaluate the effects of total thyroid resection on the exocrine pancreatic ultrastructure in both early and late stages of hypothyroidism in experiment.

Material and Methods - The experimental study was carried out on 40 mature white male rats of weight 180 to $200 \mathrm{~g}$ divided into two groups: group I - intact rats, which were kept in normal vivarium conditions (control group) and group II with experimental hypothyroidism modelled by total thyroidectomy. At the $14^{\text {th }}$ and $100^{\text {th }}$ day after thyroidectomy the animals of both groups were sacrificed under thiopental sodium anesthesia and samples of pancreatic tissue were prepared for electron microscopic study.

Results - The study of exocrine pancreatic parenchyma showed the diversity of the cellular composition. Light and dark cells were visualized in animals of the control and experimental groups. It was associated with different stages of the cellular secretory cycle. The number of zymogen granules of was sharply reduced in the apical poles of secretory cells, and were completely absent in some cells.

Conclusion - The data obtained indicate violations of the ultrastructural organization of pancreatic acinocytes at the early stage after surgery ( $14^{\text {th }}$ day). The prolongation of hypothyroidism state (up to 100 days) leads to a number of changes in all structural components of secretory cells that affect the functional activity of acinocytes. Further existence of hypothyroidism is accompanied by the development of dystrophic processes.
\end{abstract}

Keywords: pancreas, hypothyroidism, rats, electron microscopy

Cite as Ostapenko OV, Kriventsov MA, Shramko YI, Yermola YA, Mostiuk EM. Electron microscopic study of changes in pancreatic exocrine secretory cells in both early and late stages of hypothyroidism. Russian Open Medical Journal 2019; 8: e0301.

Correspondence to Maxim A. Kriventsov. Address: 5/7, Lenin Boulevard, Simferopol, 295000, Russia. Phone: +7-9787092328. E-mail: maksimkgmu@mail.ru.

\section{Introduction}

Processes of physiological development, functioning and growth of organs, systems and the whole organism are possible only under the condition of uninterrupted functioning and adequate response to the environment. Inadequate production of hormones (endocrine disorders in the form of hypo- and hyperfunction of endocrine glands) in the organism is a serious pathology that causes disorders in all tissues and organs. One of the most common endocrine pathologies is a disturbance of thyroid gland functions (hypothyroidism of different origin) [1]. The clinical manifestations of hypothyroidism are different and depend on the duration and severity of thyroid hormones' deficiency. In addition, the manifestations depend on age and the presence of concomitant diseases. Hypothyroidism can last a long time under the masks of anemia, depression, infertility and amenorrhea, nephritis and polyserositis, coronary heart disease as well [1,2]. Disorders caused by hypothyroidism are concealed by manifestations of a main disease. These disorders are accompanied by significant changes in hemodynamics, functions of heart, kidneys, and many other organs $[3,4,5]$, leading to late diagnosis of thyroid diseases. Often, the violations arising in other organs are so prominent that they become the leading ones. Besides that, numerous studies confirm the relationships of hypothyroidism with hypertension, coronary heart disease and lipid metabolism disorders, carbohydrate metabolism disorders, hypersympathicotonia and insulin resistance $[6,7]$. On the other hand, combined pathology of the gastrointestinal tract, hepatobiliary system and thyroid gland is an urgent modern problem. It takes place due to the steady rise of liver, biliary tract and pancreas pathology, as well as their combination with the thyroid gland disorders [8].

The tendency to increased incidence of thyroid diseases is associated with the consequences of the Chernobyl accident. The number of thyroid lesions has been grown from year to year [9]. The importance of thyroid pathology has also increased in recent years because of the environmental pollution and iodine deficiency $[1,10]$. Due to the steady increase in the frequency of thyroid diseases that requires surgery, the problem of postoperative hypothyroidism is becoming increasingly urgent [11]. At the same time, there is very limited information about changes in the structure, and particularly ultrastructure, of pancreatic cells in hypothyroidism. However, the pancreas is one of the key organs in the development of multi-organ failure and is directly related to the adaptive capacity of the body. In patients with hypothyroidism, 
violations of exocrine and endocrine functions of the pancreas are often revealed. The relationship of the pancreas with the thyroid gland is not completely disclosed; although the structural and functional features of the insular apparatus of the pancreas under hypothyroidism are described in the literature in details [12-14], the peculiarities of pancreatic lesions in hypothyroidism remain insufficiently studied.

Taking in consideration all the above mentioned, aim of this study was to evaluate the effects of total thyroid resection on the exocrine pancreatic ultrastructure in both early and late stages of hypothyroidism in experiment.

\section{Material and Methods}

The study of ultrastructural changes in pancreatic secretory cells under the hypothyroidism condition was carried out on 40 mature white male rats of weight 180 to $200 \mathrm{~g}$. All the experiments were carried out in compliance with the international principles of the European Convention for the protection of vertebrates used for experimental and other scientific purposes [15].

The animals were divided into two groups: group I - intact rats, which were kept in normal vivarium conditions (control group). In the animals of group II pronounced hypothyroidism was modelled. The hypothyroidism condition was modeled by total thyroidectomy, according to the standard described protocol [16]. Intact rats underwent the same surgical procedures without removal of the thyroid gland. Control of hypothyroidism was performed by determining the level of free thyroxin in blood plasma by enzyme immunoassay.

At the $14^{\text {th }}$ and $100^{\text {th }}$ day after thyroidectomy the control and experimental animals were sacrificed under thiopental sodium anesthesia. Such terms of the experiment with hypothyroidism after thyroidectomy were chosen to evaluate both early ( 14 days) and late (100 days) changes in target organ (pancreas) based on one of the earliest investigations performed by Knigge [17]. For transmission electron microscopic (TEM) examination, pancreatic fragments of size $1 \mathrm{~mm}^{3}$ were fixed in $2.5 \%$ glutaraldehyde in phosphate buffer $(\mathrm{pH} 7.4)$ with adding of $1 \% \mathrm{OsO}_{4}$ solution, followed by dehydration in increasing concentration of alcohols and acetone. Samples were embedded in EPON-Araldite blocks according to the generally accepted method.

Ultrathin sections were made using LKB III ultramicrotome (LKB, Sweden), contrasted with lead citrate and uranyl acetate, and examined under PEM-125K electron microscope (Sumy, Ukraine).

\section{Results}

Electron microscopic study of pancreatic acinocytes in experimental animals showed the heterogeneity of their population. Among the secretory cells "dark" and "light" cells were present, indicating asynchrony of the functional activity and the presence of acinocytes at different stages of the secretory cycle. "Dark" cells were mostly presented by acinar cells, and "light" cells were located centro-acinar.

\section{Ultrastructure of exocrine pancreatic cells following 14 days after thyroidectomy}

At the $14^{\text {th }}$ day of pronounced hypothyroidism, the great portion of the parenchyma was presented by "light" mononuclear secretory cells. In addition, "dark" mono- and bi- nuclear acinocytes and "light" bi-nuclear acinocytes were found in the parenchyma of the exocrine pancreas (see Figure 1). Electron microscopic study revealed that the ultrastructural changes affected all organelles of acinocytes: mitochondria, synthetic apparatus, represented by the cisternae of the granular endoplasmic reticulum and Golgi apparatus, as well as secretory granules.

Compared with the control, the number of mitochondria in the cells was significantly reduced. They also differed in shape and size. Most of the organelles had medium size, rounded shape, with moderate electronic density. There was a small part of the mitochondria of the rod-shaped, elongated form. The number of cristae in mitochondria in comparison with the intact group was drastically reduced (see Figure 2).

The integrity of the granular endoplasmic reticulum was disrupted. Cisternae partially lost their parallel course, arranging chaotically, were shortened, forming extensions at the ends. As a result of expansion of the granular endoplasmic reticulum cisternae, vacuolated formations of small and medium size were formed with almost no large vesicles in most cells (see Figure 3 ). Some portions of basal membrane were unevenly expanded. Ribosomes retained their location on the membranes of the endoplasmic reticulum in the form of polysomes (see Figure 4).

Due to the extended cisternae and the presence of a large number of vesicles, the Golgi apparatus was visualized between the cisternae of the granular endoplasmic network. Immature secretory granules with an electron-light matrix were observed near the Golgi apparatus. Zymogen granules, heterogenic in size and electron density, were present at the apical part of the acinar cells (see Figure 1 and Figure 2). The content of a small number of detected granules was recognized as a prozymogen. Despite the difference in the qualitative composition of the granules, their number does not differ significantly compared to the control.

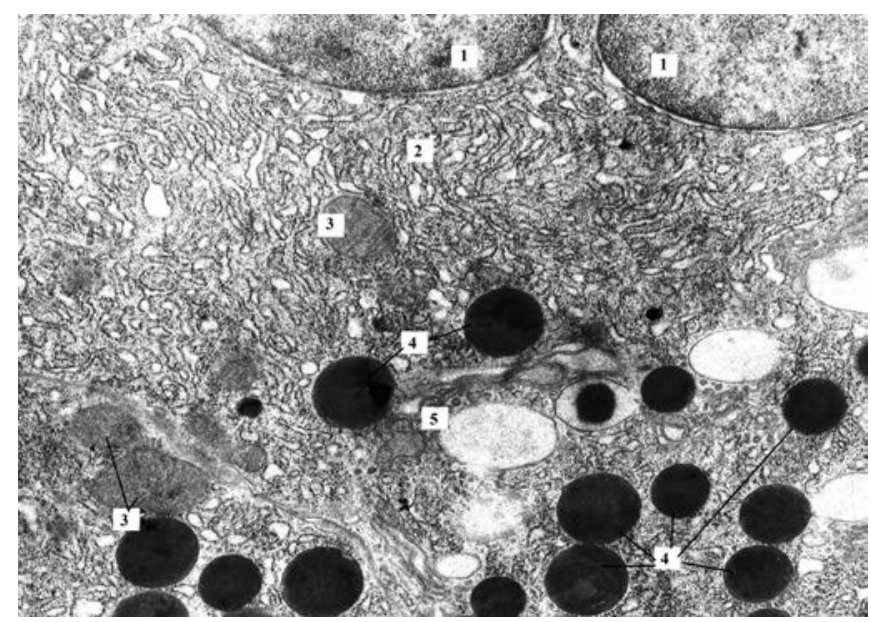

Figure 1. Bi-nucleated pancreatic acinocyte of rat with hypothyroidism (14th day after surgery). The perinuclear space is unevenly expanded (similar to cisterns of granular endoplasmatic reticulum). Granular endoplasmic reticulum loses its parallel course and forms minor extensions. In the area of the Golgi complex, zymogen granules of different electron density and size are present. TEM. X8000. 1 - nucleus; 2 - granular endoplasmic reticulum; 3 - mitochondria; 4 - zymogen granules; 5 - Golgi complex. 


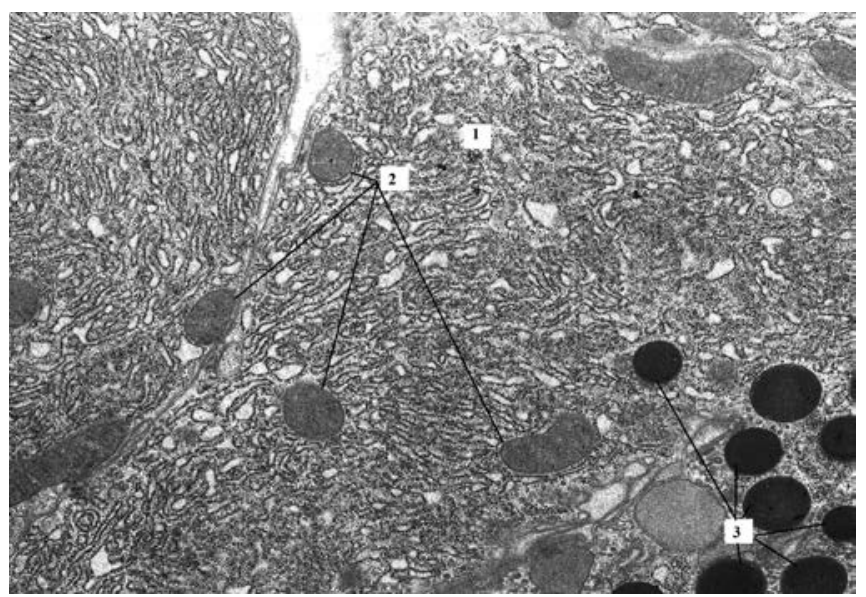

Figure 2. Pancreatic acinocytes of rat with hypothyroidism $\left(14^{\text {th }}\right.$ day after surgery). The size and shape of mitochondria varies (round, oval, rod-shaped). The mitochondrial matrix is homogenized and has moderate electron density. Expansions of the granular endoplasmatic reticulum form small vacuoles. TEM. X6400. 1 - granular endoplasmic reticulum; 2 - mitochondria; 3 zymogen granules.

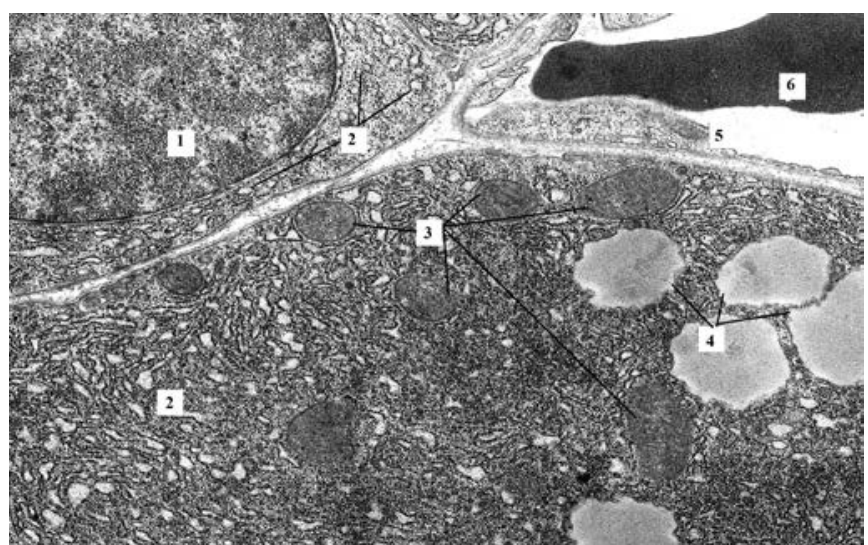

Figure 3. The fragment of pancreatic acinocyte of rat with hypothyroidism $\left(14^{\text {th }}\right.$ day after surgery). In the basal part of the acinocyte, the granular endoplasmatic reticulum loses its parallel course and looks like shortened cisternae and vesicles. The basal membrane of epithelial cells (acinocytes, endotheliocytes) is thickened. TEM. X6400. 1 - nucleus; 2 - granular endoplasmic reticulum; 3 - mitochondria; 4 - vacuoles; 5 - hemocapillary; 6 red blood cell.

Ultrastructure of exocrine pancreatic cells following 100 days after thyroidectomy

The parenchyma of the organ was characterized by heterogeneity of cellular population, with a predominance of "light" mononuclear secretory cells. In addition, "dark" mono- and bi-nucleated acinocytes and "light" bi-nucleated acinocytes were noticed. The predominance of "light" cells in the pancreatic parenchyma was rather pronounced in the late stages of hypothyroidism than in the early period. Some cells with electron-light cytoplasm were in the state of dystrophic changes of their ultrastructural organization.

Mitochondria were large, rounded with an electron-dense matrix, partial or complete absence of cristae. In some cases there was a violation of the integrity of the inner and/or outer membranes (see Figure 5). In small areas of the cytoplasm there were myelin-like structures formed instead of mitochondria.

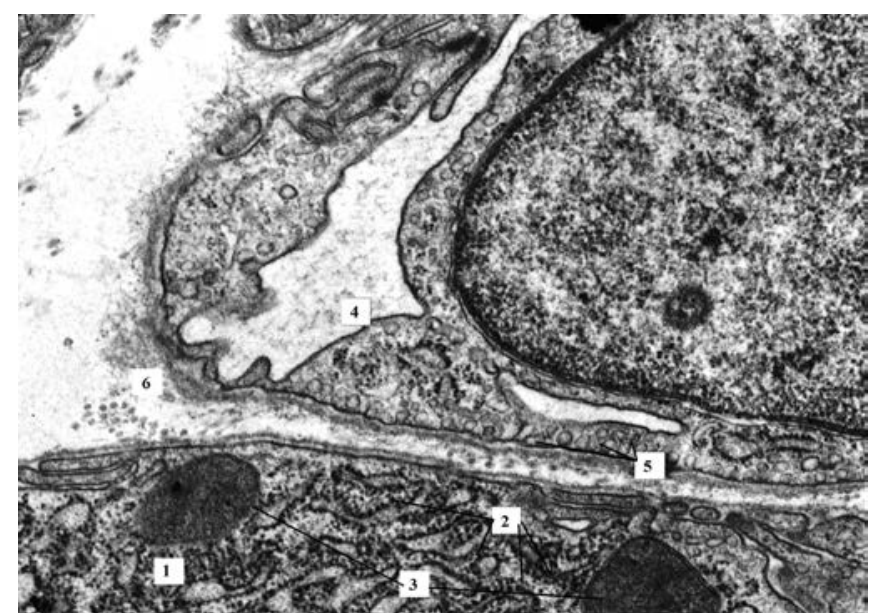

Figure 4. The fragment of pancreatic acinocyte of rat with hypothyroidism $\left(14^{\text {th }}\right.$ day after surgery). The basal membrane is unevenly expanded. In the basal part, the cell membrane of the acinocyte forms invaginations. The mitochondrial matrix has moderate electron density, the cristae are not visualized. The endotheliocyte cytoplasm is filled with micropinocytosis vesicles. TEM. X16000. 1 - acinocyte; 2 - granular endoplasmic reticulum; 3 mitochondria; 4 - hemocapillary; 5 - micropinocytosis vesicles; 6 - connective tissue between cells.

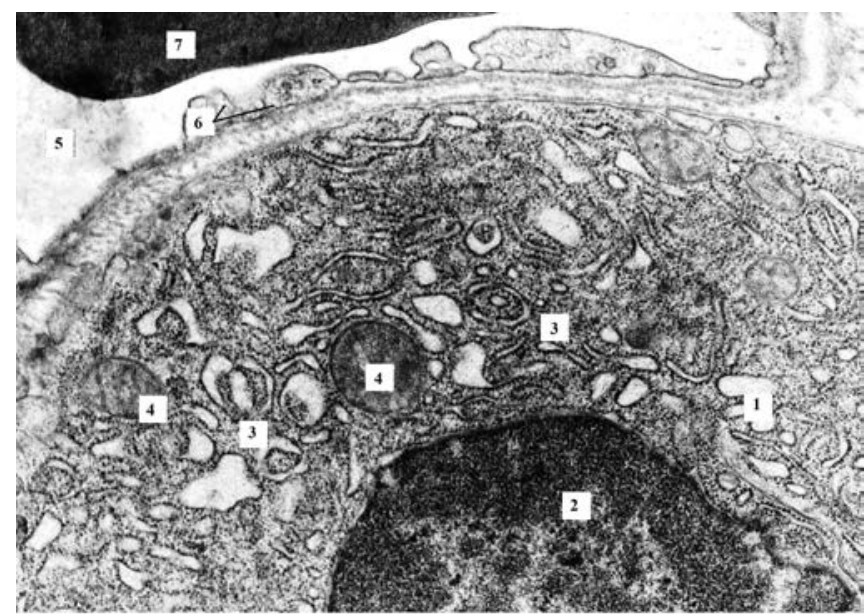

Figure 5. The fragment of pancreatic acinocyte of rat with hypothyroidism (100 days after surgery). The nucleus of the acinocyte has irregular edges. The cytoplasm is filled with shortened cisterns of granular reticulum and vesicles. The inner, in some cases, and outer mitochondrial membranes lose their integrity. TEM. X12000. 1 - acinocyte; 2 - nucleus; 3 - granular endoplasmic reticulum; 4 - mitochondria; 5 - hemocapillary; 6micropinocytosis vesicles; 7 - red blood cell.

A pronounced decrease in the number of zymogen granules in the apical part of the secretory cells was revealed. Additionally, they were completely absent in some cells. Mature, fully formed secretory granules were seldom. Granules were characterized by small size and moderate electron density (see Figure 6).

Most of the cells were characterized by significant changes in the protein-synthesizing apparatus. The cisternae of the granular endoplasmic reticulum were shortened, expanded and lost their typical parallel arrangement (see Figure 7 and Figure 8). The cytoplasm was filled with numerous vesicles, with variety of shape and size, resulting in "foamy" appearance (see Figure 6). There was a decrease in the number of ribosomes on the surface of granular endoplasmic reticulum membranes and in the cytoplasm. A large number of 
vesicles of enlarged and shortened cisternae of the endoplasmic reticulum led to poor visualization of the Golgi apparatus.

\section{Discussion}

It is well known, that the energy and plastic capabilities of the organism are depleted with increasing strength and duration of adverse factors, which lead to dissonance in the organism and to the formation of diseases. Hypothyroidism causes both persistent development of thyroid hormone deficiency and decrease of their biological activity, leading to affection of various systems and organs, including liver and pancreas. This is consistent with the clinical picture: functional insufficiency of the pancreas and thyroid gland in the combination of two diseases has a direct correlation [18].

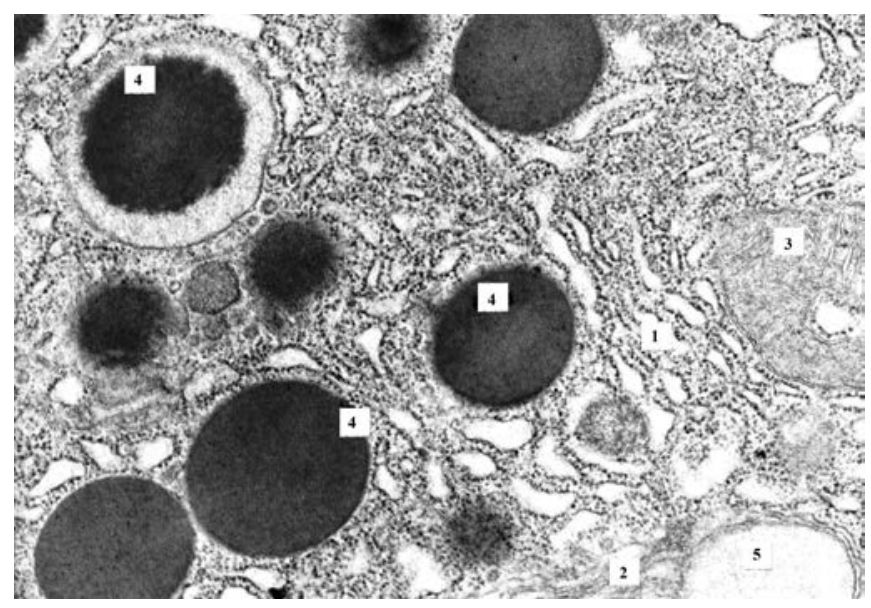

Figure 6. Pancreatic acinocyte of rat with hypothyroidism (100 days after surgery). The cytoplasm is filled with shortened cisternae of granular and agranular endoplasmatic reticulum and vacuoles. Zymogen granules have an unclear contour. TEM. X16000. 1 - granular endoplasmic reticulum; 2 - agranular endoplasmic reticulum; 3 - mitochondria; 4 - zymogen granules; 5 - vacuole.

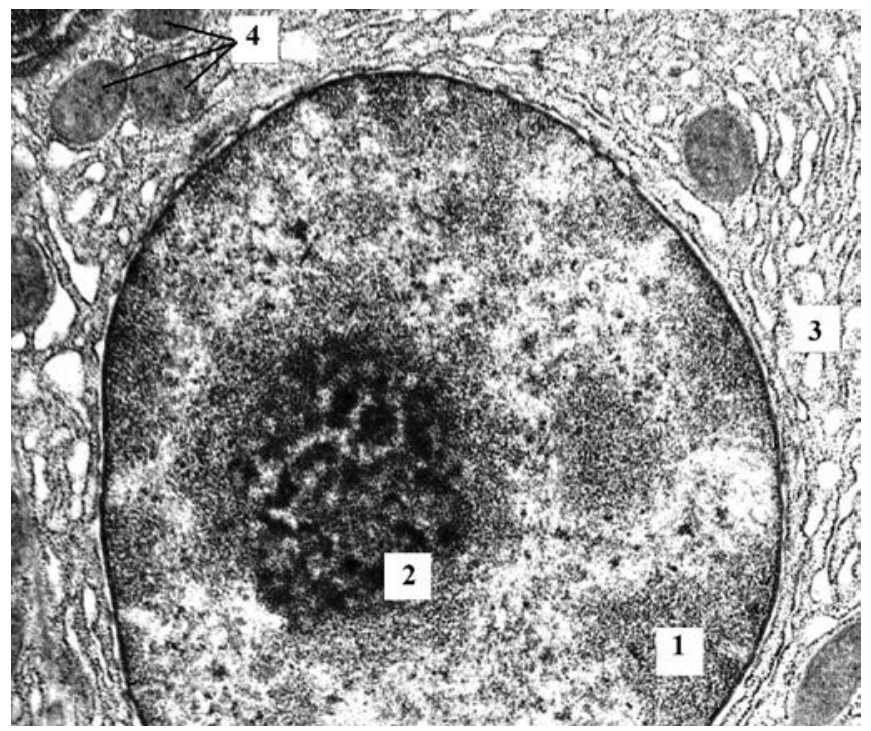

Figure 7. The fragment of pancreatic acinocyte of rat with hypothyroidism (100 days after surgery). Perinuclear space is expanded and contains a lot of expanded cisternae of granular endoplasmatic reticulum. A number of nuclei of the cells contain large nucleoli. TEM. X12000. 1 - nucleus; 2 nucleolus; 3 - expanded cisternae of the granular endoplasmic reticulum; 4-mitochondria.
The study of exocrine pancreatic parenchyma showed that the secretory cellular population of the organ was diverse. "Dark" and "light" cells were visualized in animals of both control and experimental groups. Such heterogeneity is tightly associated with their histotopographical location - acinar and centro-acinar, respectively. Their morphology is heterogeneous, and functional state of acinar and centro-acinar cells is thought to be different according to the different stages of the cellular secretory cycle [19]. However, the predominance of "light" cells with less functional activity was associated with pathological changes in animals of experimental groups, be more pronounced in the late stages of hypothyroidism than in the early period.

Detailed changes in acinocytes were identified in the analysis of their ultrastructural organization. Minor deviations from the physiological state in the mitochondrial ultrastructure indicate that the energy system of the cell in the early stages of hypothyroidism (14 days) copes with the functional load. The expansion of the cisternae in granular endoplasmic reticulum was not found in all cells, which is associated, firstly, with the asynchronous secretory cycle, and secondly, the adaptive properties of secretory cells. A variety of sizes and electron density of zymogenic granules indicated a different degree of ripening of secretion product. In some cases, electron-dense granules occurred in extended cavities of granular endoplasmic reticulum (intracisternally), which differed from mature zymogenic granules by lower electron density and smaller size. Generally, these observations were consistent with the experimental study carried out by Blanco-Molina et al [20]. In particular, it was shown that 4 weeks (28 days) after thyroidectomy exocrine acinocytes of pancreas in rats characterized by less number of zymogen granules with less density. Authors made conclusion that exocrine pancreas is a thyroid hormone responsive tissue [20].

According to the results of ultrastructural analysis, it is important to note that the ultrastructural changes in exocrine portion of the pancreas observed on the $14^{\text {th }}$ day after the operation were initial and probably partially reversible. With an increase in the duration of the experiment and a decrease in the reserve of adaptation, morphological and functional lesions of the pancreas remained, which could be one of the etiological factors of chronic diseases and development of the multi-organ failure. Pancreatic acinocytes at the $100^{\text {th }}$ day of the experiment were characterized by the pronounced ultrastructural disturbances in the mitochondria, endoplasmic reticulum, and Golgi complex. A number of cells contained myelinlike structures. Severe changes of the ultrastructure of acinocytes cytoplasmic components point toward energy insufficiency of cells in the presence of increased lipid peroxidation and hypoxia. The predominance of the agranular endoplasmic reticulum over the granular one led to the condition of "no maturation" in secretory granules and, consequently, to the violation of cells' status.

The above mentioned violation was not only morphological, but also functional. As a result, in the apical poles of secretory cells, the number of granules of zymogen was significantly reduced, and in some cells, they were completely absent. Practically no mature secretory granules were found, and the present ones were characterized by small size and moderate electron density compared to the control. Such changes could be interpreted as a vacuolar degeneration of exocrine secretory cells of the pancreas under the condition of postoperative hypothyroidism. 


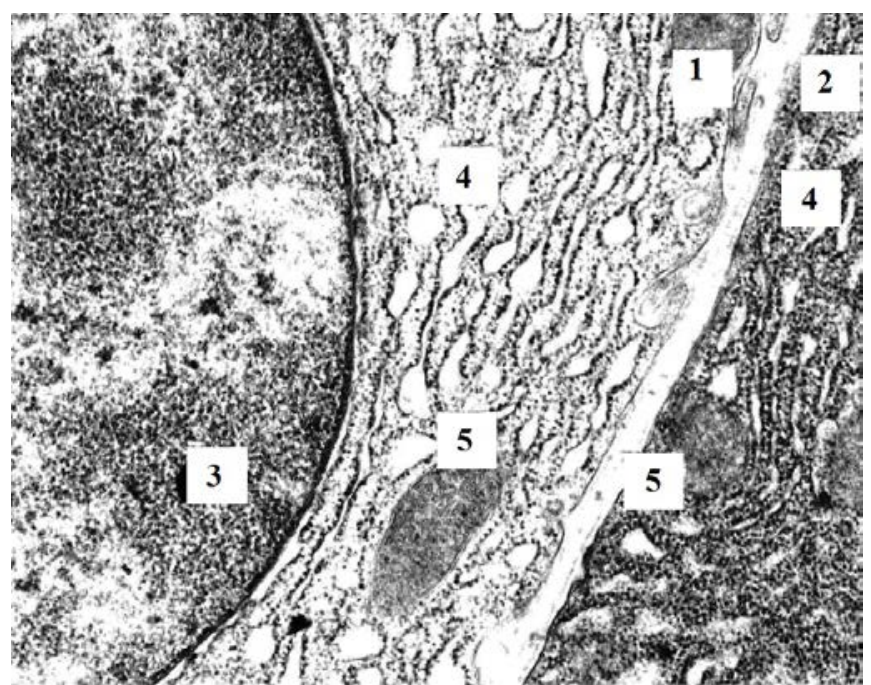

Figure 8. Pancreatic acinocytes of rat with hypothyroidism (100 days after surgery). The cytoplasm of "dark" and "light" acinocytes is filled with expanded cisternae of the granular endoplasmic reticulum and mitochondria. TEM. X20000. 1 - "light" acinocyte; 2 - "dark" acinocyte; 3 - nucleus; 4 - granular endoplasmic reticulum; 5 - mitochondria.

In conclusion, based on current literature data, there is evidence of a close relationship between the thyroid gland and the pancreas, confirmed by the expression of thyroid hormone receptors on the pancreatic secretory cells [21]. Although the role of these regulatory signals is not fully elucidated, there is evidence of the involvement of these mechanisms in the recovery of the pancreas after injury involving the recently discovered genes encoding proteins (syncollin and FGF21 protein) that regulate the synthesis, transport and exocytosis of zymogen granules [22, 23]. Considering the revealed changes and the fact that the excretory part of the pancreas is a tissue sensitive to thyroid hormones, it can be assumed that the experimental deficiency of thyroid hormones led to down-regulation of mentioned above genes described above with a corresponding damage of mainly exocytosis (on $14^{\text {th }}$ day), and further - synthesis and secretion of zymogen granules (on $100^{\text {th }}$ day), along with pronounced changes in protein-synthesizing and energy cellular apparatus.

\section{Conclusion}

The data obtained indicate violations of the ultrastructural organization of pancreatic acinocytes at the early stage after surgery $\left(14^{\text {th }}\right.$ day). The degree of ultrastructure disturbance increased with the increase of the experiment period up to 100 days after the operation and led to a number of changes in all structural components of secretory cells that affect the functional activity of acinocytes, including depletion of zymogen granules. Further existence of hypothyroidism was accompanied by the development of dystrophic processes.

\section{Study limitations}

The present experimental study was performed on mature Wistar rats under condition of hypothyroidism as a result of total thyroidectomy. Timeline of the study included 14-days and 100-days evaluations after surgery. Due to this, this study is limited only to those experimental conditions that have been modeled. Also, there are reasonable limitations related to the extrapolation of the obtained data to the humans, taking into account the species differences in the adaptive reserves and peculiarities of endocrine regulation.

\section{Conflict of interest}

The authors declare that they have no conflict of interest.

\section{Ethical approval}

All applicable international, national, and/or institutional guidelines for the care and use of animals were followed. All procedures performed in the study involving animals were in accordance with the ethical standards of the institution or practice at which the study was conducted. The study was approved by the Institutional Committee on Bioethics (Protocol No. 8 dated 15.03.2016) and is consistent with the International Guidelines for the Care and Use of Laboratory Animals published by the US NIH (No. 8523,1985 ) and Guide for the Care and Use of Laboratory Animals (2009).

\section{References}

1. Chaker L, Bianco AC, Jonklaas J, Peeters RP. Hypothyroidism. Lancet 2017; 390(10101): 1550-1562. https://doi.org/10.1016/s01406736(17)30703-1.

2. Sun J, Hui C, Xia T, Xu M, Deng D, Pan F, et al. Effect of hypothyroidism on the hypothalamic-pituitary-ovarian axis and reproductive function of pregnant rats. BMC Endocr Disord 2018; 18(1): 30 https://doi.org/10.1186/s12902-018-0258-y.

3. Gavin LA. The diagnostic dilemmas of hyperthyroxinemia and hypothyroxinemia. Adv Intern Med 1988; 33: 185-203. https://www.ncbi.nlm.nih.gov/pubmed/3278505.

4. Tachman ML, Guthrie GP. Hypothyroidism: diversity of presentation. Endocr Rev 1984; 5(3): 456-465. https://doi.org/10.1210/edrv-5-3$\underline{456}$.

5. Canaris GJ, Steiner JF, Ridgway EC. Do Traditional Symptoms of Hypothyroidism Correlate with Biochemical Disease? J Gen Intern Med 1997; 12(9): 544-550. https://doi.org/10.1046/j.15251497.1997.07109.x.

6. Udovcic M, Pena RH, Patham B, Tabatabai L, Kansara A. Hypothyroidism and the Heart. Methodist Debakey Cardiovasc J 2017; 13(2): 55-59. https://www.ncbi.nlm.nih.gov/pubmed/28740582.

7. Lishchuk O, Kikhtyak O, Moskva K. The peculiarities of correlation between insulin resistance, carbohydrate and lipid metabolism indices in patients with Graves' disease. EUREKA: Health Sciences 2017; (1): $3-$ 8. https://doi.org/10.21303/2504-5679.2017.00272.

8. Daher R, Yazbeck T, Jaoude JB, Abboud B. Consequences of dysthyroidism on the digestive tract and viscera. World J Gastroenterol 2009; 15(23): 2834-2838. https://doi.org/10.3748/wig.15.2834

9. Tronko M, Brenner AV, Bogdanova T, Shpak V, Oliynyk V, Cahoon EK, et al. Thyroid neoplasia risk is increased nearly 30 years after the Chernobyl accident. Int J Cancer. 2017; 141(8): 1585-1588. https://doi.org/10.1002/ijc.30857.

10. Rogan WJ, Paulson JA, Baum C, Brock-Utne AC, Brumberg HL, Campbell $C C$, et al. lodine deficiency, pollutant chemicals, and the thyroid: new information on an old problem. Pediatrics 2014; 133(6): 1163-1166. https://doi.org/10.1542/peds.2014-0900.

11. Beisa V, Kazanavicius D, Skrebunas A, Simutis G, Ivaska J, Strupas K. Prospective Analysis of Risk for Hypothyroidism after Hemithyroidectomy. Int J Endocrinol 2015; 2015: 313971. https://doi.org/10.1155/2015/313971.

12. Godini A, Ghasemi A, Karbalaei N, Zahediasl S. The effect of thyroidectomy and propylthiouracil-induced hypothyroidism on insulin secretion in male rats. Horm Metab Res 2014; 46(10): 710-716. https://doi.org/10.1055/s-0034-1370962.

13. Farahani H, Ghasemi A, Roghani M, Zahediasl S. Effect of neonatal hypothyroidism on carbohydrate metabolism, insulin secretion, and pancreatic islets morphology of adult male offspring in rats. $J$ 

Endocrinol
Invest
2013;
36(1):
44-49.

https://www.ncbi.nlm.nih.gov/pubmed/22732210.

14. Rodríguez-Castelán J, Martínez-Gómez M, Castelán F, Cuevas E. Hypothyroidism Affects Vascularization and Promotes Immune Cells Infiltration into Pancreatic Islets of Female Rabbits. Int J Endocrinol 2015; 2015: 917806. https://doi.org/10.1155/2015/917806.

15. European Convention for the Protection of Vertebrate Animals used for Experimental and other Scientific Purposes (ETS N 123). Strasbourg, 18 March 1986. http://docs.cntd.ru/document/901909691.

16. Francisco JC, Cunha RC, Cardoso MA, Simeoni RB, Guarita-Souza LC, Miyague NI. The Effects of Total Thyroidectomy on Cardiac Function in Old Rats using Echocardiographic Measures. J Clin Exp Cardiolog 2013; S11: 006. https://doi.org/10.4172/2155-9880.S11-006.

17. Knigge KM. Cytology and growth hormone content of rat's pituitary gland following thyroidectomy and stress. Anat Rec 1958: 130(3): 543551. https://doi.org/10.1002/ar.1091300306.

18. Chen C, Xie Z, Shen Y, Xia SF. The Roles of Thyroid and Thyroid Hormone in Pancreas: Physiology and Pathology. Int J Endocrinol 2018; 2018: 2861034. https://doi.org/10.1155/2018/2861034.

19. Cruickshank AH, Benbow EW. Normal microscopic structure. In: Pathology of the pancreas. London, UK: Springer, 1995: 1-12. https://doi.org/10.1007/978-1-4471-3005-5 1.

20. Blanco-Molina A, González-Reyes JA, Torre-Cisneros J, López-Miranda $J$, Nicolás M, Pérez-Jiménez F. Effects of hypothyroidism on the ultrastructure of rat pancreatic acinar cells: a stereological analysis. Histol Histopathol 1991; 6(1): 37-42. https://www.ncbi.nlm.nih.gov/pubmed/1806054.

21. Mastracci TL, Evans-Molina C. Pancreatic and Islet Development and Function: The Role of Thyroid Hormone. J Endocrinol Diabetes Obes 2014; 2(3): 1044. https://www.ncbi.nlm.nih.gov/pubmed/25506600.

22. Antonin W, Wagner M, Riedel D, Brose N, Jahn R. Loss of the Zymogen Granule Protein Syncollin Affects Pancreatic Protein Synthesis and Transport but Not Secretion. Mol Cell Biol 2002; 22(5): 1545-1554. https://doi.org/10.1128/MCB.22.5.1545-1554.2002.

23. Boggs $\mathrm{K}$, Wang $\mathrm{T}$, Orabi Al, Mukherjee $\mathrm{A}$, Eisses JF, Sun $\mathrm{T}$, et al. Pancreatic gene expression during recovery after pancreatitis reveals unique transcriptome profiles. Sci Rep 2018; 8(1): 1406. https://doi.org/10.1038/s41598-018-19392-0.

\section{Authors:}

Olga V. Ostapenko - PhD, Associate Professor of Wine-Making and Technologies of Fermentative Productions, Academy of Bioresources and Environmental Management, V.I. Vernadsky Crimean Federal University, Simferopol, Russia. https://orcid.org/0000-0002-2935-1985.

Maxim A. Kriventsov - MD, DSc, Professor, Head of the Department of Pathological Anatomy with a Sectional Course, Medical Academy n.a. S.I. Georgievsky, V.I. Vernadsky Crimean Federal University, Simferopol, Russia. https://orcid.org/0000-0001-5193-4311.

Yuliana I. Shramko - PhD, Associate Professor, Department of General and Clinical Pathophysiology, Medical Academy n.a. S.I. Georgievsky, V.I. Vernadsky Crimean Federal University, Simferopol, Russia. https://orcid.org/0000-0003-4946-7317.

Yulianna A. Yermola - PhD, Associate Professor of the Department of Pathological Anatomy with a Sectional Course, Medical Academy n.a. S.I. Georgievsky, V.I. Vernadsky Crimean Federal University, Simferopol, Russia. https://orcid.org/0000-0003-4474-3714.

Elena M. Mostiuk - PhD, Senior Teacher of the Department of Pathological Anatomy with a Sectional Course, Medical Academy n.a. S.I. Georgievsky, V.I. Vernadsky Crimean Federal University, Simferopol, Russia. https://orcid.org/0000-0002-4310-5801. 